\title{
LA FORMA COMO DEBE DECIDIR EL JUEZ HÉRCULES. DESCRIPCIÓN Y ANÁLISIS DE LA TEORÍA DE LA ARGUMENTACIÓN JURÍDICA DESDE LA VISIÓN DE RONALD DWORKIN. ESTUDIO DE CASO BASADO EN LA JURISPRUDENCIA COLOMBIANA
}

\author{
THE WAY HOW JUDGE HERCULES SHOULD DECIDE. ANALYSIS AND \\ DESCRIPTION OF THE THEORY OF LEGAL ARGUMENTATION FROM \\ THE VISION OF RONALD DWORKIN. ESTUDY OF CASE BASED IN \\ THE COLOMBIAN JURISPRUDENCE
}

\author{
David Modesto Güette Hernández \\ Angie Carolina Rodríguez Cuadrado ${ }^{* *}$
}

\begin{abstract}
RESUMEN: A lo largo de estas líneas se pretende realizar una reconstrucción de la metodología decisoria del juez Hércules, para luego, mostrar a los lectores la importancia que supone la aplicación de los criterios de integridad y coherencia al momento de interpretar las normas jurídicas, así como la incidencia que tienen estos enfoques en las decisiones judiciales, la manera en cómo varían estas cuando se omiten y cuando se toman en consideración; lo anterior se hará aplicado a la interpretación que se le otorgó a la regla contenida en el artículo 121 del Código General del Proceso (Estatuto Procesal Colombiano) por parte de los jueces de la jurisdicción ordinaria, quienes al omitir en su actividad interpretativa los criterios de integridad y coherencia devinieron en la previsible declaratoria de inexequibilidad de la nulidad de pleno derecho contenida en esta norma por parte de la Corte Constitucional.
\end{abstract}

Palabras clave: Integridad, coherencia, interpretación, norma jurídica, decisiones judiciales.

ABSTRACT: Along these lines, it is intended to show to the readers the importance that supposes the application of the criteria of integrity and coherence to the moment to interpret the juridical norms, as well as the incidence that these approaches have in the judicial decisions, the way in which these vary when they are omitted and when they are taken into consideration; the foregoing will be applied to the interpretation that was granted to the rule contained in the article 121 of the General Code of the Process (Colombian Procedural Statute) by the judges of the ordinary jurisdiction, who by omitting the criteria of integrity and coherence, became the foreseeable declaration of non-enforceability of the nullity of full right contained in this norm by the part of the Constitutional Court.

Keywords: Integrity, coherence, interpretation, legal norm, judicial decisions.

\footnotetext{
Abogado egresado de la Universidad Libre de Barranquilla, especialista en responsabilidad y seguros, Magister en Derecho y Doctor en Derecho Egresado de la Universidad del Norte. Juez de la Republica.

Docente Universidad Libre de Barranquilla, e Investigador INCOM. Dirección electrónica: guettedavid@hotmail.com. Código postal: 080002181 .

* Abogada egresada de la Universidad del Magdalena, graduada con distinción meritoria a la mejor egresada de la facultad. Dirección electrónica: angiecrodriguezc@gmail.com. Código postal: 080002181.
} 


\section{INTRODUCCIÓN}

En las presentes líneas pretendemos describir la manera en la que debe decidir el prototipo de juez dworkiniano, denominado por él cómo juez Hércules. Para esto se realiza una sistematización a partir de las lecturas de Ronald Dworkin con el propósito de reconstruir lo que sería su teoría de la argumentación jurídica, o, dicho de otro modo, la metodología argumentativa que debe utilizarse en las decisiones judiciales. Para realizar la reconstrucción planteada, y con el propósito de ilustrar y concretarla en la práctica judicial, se utilizará como punto de referencia un debate que se suscitó en la jurisprudencia colombiana en torno a la aplicabilidad de una figura procesal denominada como nulidad de pleno derecho.

El trabajo tendrá 2 divisiones fundamentales: (i) la construcción o reconstrucción de lo que sería la teoría de argumentación jurídica de Ronald Dworkin; y (ii) La manera en cómo ella se aplicaría en la práctica judicial. La primera fase, será eminentemente teórica, y abarca una metodología básica bibliográfica. La segunda fase es un análisis jurisprudencial, donde se identifican todas las decisiones que se emitieron en torno a la interpretación del artículo 121 del CGP, para luego realizar una comparación entre estas y la metodología identificada.

\section{LA NOVELA EN CADENA COMO CRITERIO ILUSTRADOR DE LA METODOLOGÍA ARGUMENTATIVA DEL JUEZ HÉRCULES DWORKINIANO}

"Muchos de los que estaban en el puerto sabían que a Santiago Nasar lo iban a matar... En realidad, mi hermana Margot era una de las pocas personas que todavía ignoraban que lo iban a matar... Nuestra casa estaba lejos de la plaza grande, en un bosque de mangos frente al río. Mi hermana Margot había ido hasta el puerto caminando por la orilla, y la gente estaba demasiado excitada con la visita del obispo para ocuparse de otras novedades. Habían puesto a los enfermeros acostados en los portales para que recibieran la medicina de Dios, y las mujeres salían corriendo de los patios con pavos y lechones y toda clase de cosas de comer, y desde la orilla opuesta llegaban canoas adornadas de flores. Pero después de que el obispo pasó sin dejar su huella en la tierra, la otra noticia reprimida alcanzó su tamaño de escándalo. Entonces fue cuando mi hermana Margot la conoció completa y de un modo brutal: Ángela Vicario, la hermosa muchacha que se había casado el día anterior, había sido devuelta a la casa de sus padres, porque el esposo encontró que no era virgen. Sentí que era yo la que me iba a morir, dijo mi hermana. Pero por más que volteaban el cuento al derecho y al revés, nadie podía explicarme cómo fue que el pobre Santiago Nasar terminó comprometido en semejante enredo. Lo único que sabían con seguridad era que los hermanos de Ángela Vicario lo estaban esperando para matarlo"1.

Relata Gabriel García Márquez, el fatal desenlace de un desprevenido habitante de una pequeña población de inmigrantes, erigida en los albores de un río que servía para esa época en una Colombia rural de canal de comunicación y comercio. Santiago Nasar habría de morir solo con leer el título de la obra y en sus iniciales páginas se podría avistar que los

1 García Márquez (1981) p. 65. 
hombres que lo esperaban con cuchillos arropados en hojas de periódico iban a ser quienes perpetraran el brutal acto, justificado en el honor mancillado de su hermana que una noche antes había sido devuelta por quien debiera ser su esposo, aduciendo que previamente había perdido la virginidad.

El lector de la "Crónica de una muerte anunciada", advertirá desde el título de la obra que alguien va a morir, y no podrá pasar por alto después de las primeras hojas que será Santiago Nasar. Si luego de dos capítulos leídos, se les encomendara la tarea de continuar escribiendo el desenlace de la historia, deberías si eres responsable con la lectura y los personajes, encontrar una forma adecuada para terminar con la vida de Santiago. Sería esta la manera como Dworkin ilustraría a sus lectores como concibe su manera de argumentar, develando dos de sus pilares: la integridad y la coherencia. Así, la metodología, tanto de la novela como de la decisión judicial, están llamadas a conectarse en esos pilares, evitando que sea el azar quien defina ya sea como se continúa con la novela o la decisión emitida por el juez.

La novela en cadena ${ }^{2}$ que se construye como una especie de red, en la que muchos novelistas se dedican a escribir en ella, debiendo quien releva a su anterior, interpretar los capítulos que ha recibido para poder escribir uno nuevo que luego se agrega a lo que recibe el siguiente novelista y así sucesivamente, requiriéndose para escribir el suyo, conocer los anteriores, de esa forma poder conservar la coherencia ${ }^{3}$ y preservar la integridad del texto.

A través de esta metáfora pretende ilustrar una metodología de argumentación. La novela en serie es la que escriben los jueces en sus providencias. De esa manera, cada uno deberá tener en cuenta lo que se ha escrito antes, para que el producto de esa novela guarde coherencia e integridad sin dejar de lado ningún aspecto de los que hasta el momento se ha escrito. Haciendo alusión con esta idea, a la mejor manera de producir derecho.

Con esta concepción del derecho, Dworkin pretende asemejar la interpretación de las normas jurídicas a la interpretación literaria, pues en ambos casos el autor debe propender por realizar la mejor interpretación de la obra, y siendo el juez uno de esos autores de la novela en cadena, tiene a su cargo la responsabilidad de determinar cuál es la interpretación que mejor se adapta al capítulo que se está desarrollando. Lo antes mencionado, supone entender que a simili las decisiones que conforman el ordenamiento jurídico se moldean teniendo en cuenta las interpretaciones precedentes y la tradición, por lo que no pueden interpretarse de manera aislada sino teniendo en cuenta lo que ha ocurrido para advertir lo que puede ocurrir.

\footnotetext{
2 A través de esta metáfora pretende ilustrar la complejidad a la que puede enfrentarse el intérprete a la hora de aplicar una norma jurídica de la cual no es autor, pues "debe tratar de que sea la mejor novela que pueda construirse como la obra de un solo autor en lugar del producto de varias manos diferentes": DwORKIN (1988) p. 167. 3 Para Ruiz (2006) p. 23: "La palabra coherencia o la alusión a que algo es coherente, en un sentido usual y común, hace referencia a la conexión, relación o unión de unas cosas, entres o ideas con otras, sin que se produzcan fisuras o contradicciones". La coherencia constituye un término con una amplia carga emotiva, y su propósito es indicar una característica positiva, de manera que en un sentido formal "es una cualidad del sistema en cuya virtud cada situación de hecho recibe un único tratamiento normativo dentro del sistema en cuestión”. PRIETO (2011) p. 131; cuando nos referimos a la noción de coherencia, hacemos referencia a la existencia de un derecho vigente constituido por un conjunto heterogéneo de disposiciones asistemáticas, dispersas incompletas, contradictorias e imprecisas, sobre las cuales debe buscarse soluciones en un nivel superior a la sola lógica e identificar los valores, intereses, objetivos y principios que apoyan cada posición.
} 
Vemos que, así como existieron en esta célebre obra de Crónica de una muerte anunciada muchos acontecimientos que permitían conocer el desenlace que le esperaba al protagonista antes de que ocurriera. Lo que Dworkin identifica como coherencia e integridad, como elementos guías para el escritor de novela, constituyen también para el juez al momento de emitir una decisión judicial, las herramientas para elegir la interpretación adecuada a las normas jurídicas que conforman el sistema. No deja de ser, sin embargo, abstracto un modelo argumentativo que utilice como referencia analógica a una novela, requiriéndose delimitar con precisión los pilares que subyacen a ambas y que permitirán precisar la propuesta.

\section{LA NOCIÓN DE INTEGRIDAD. PRIMERO DE LOS PILARES NECESARIOS EN EL MODELO ARGUMENTATIVO DE RONALD DWORKIN}

Es importante destacar que para Dworkin el derecho es una práctica interpretativa que toma en consideración la integridad del sistema ${ }^{4}$. Esa práctica interpretativa no es meramente descriptiva, sino por el contrario, incorpora un contenido moral y holista, en el que necesariamente deba identificarse el propósito y los valores que dan sentido al significado de los conceptos. A partir de esta idea sostendremos que la propuesta argumentativa de Dworkin, identifica una fase de metodología jurídica, y otra de metodología ética, ambas imbuidas dentro del concepto de integridad. La noción de integridad es entonces el eje de lo que podemos llamar como su propuesta argumentativa.

La noción de integridad tiene como propósito atribuir un orden o sistematicidad a un conjunto de normas jurídicas positivas, pero, además, constituirse en un ideal ético que debe perseguirse o tratar de alcanzarse en la mayor medida de lo posible al momento de decidir. La primera visión supone entender el sistema normativo como un panorama que amalgama lo legal con lo constitucional; lo que implica cambiar el paradigma hermenéutico realizando un viraje obligatorio de uno literal ${ }^{5}$ o sistemático-literal ${ }^{6}$, inclusive uno gené-

\footnotetext{
4 DwOrKIn (1988) p. 164.

5 El método literal desarrollado por la escuela de la exégesis propugna la completud y racionalidad a priori - de la ley, basado en la idea de un legislador racional y sabio, que se arropaba con un manto de divinidad, producto de la creencia influenciada por el iusnaturalismo teológico medieval según la cual, la ley se conformaba por el contenido del querer de Dios, conllevando a que el juez como aplicador del derecho, debiera atenerse al sentido literal de lo establecido en ella. Sostiene Solano (2016) p .171: esta escuela, que tuvo su origen en Francia con la codificación napoleónica, se soportó en el llamado "mito del legislador racional”; la expresión "exégesis" tiene su origen en la hermenéutica de los textos sagrados; exégesis es, precisamente, "interpretación de los textos sagrados".

${ }^{6}$ Cuando planteamos el necesario viraje del paradigma interpretativo no nos referimos únicamente al que se lleva a cabo a partir de la interpretación gramatical o exegética, incluimos la genética o intención del legislador e inclusive la sistemática, en esto nos apoyamos con GARCía (2003) p. 96 y ss; cuando sostiene que hablar de una interpretación eminentemente sistemática, supone necesariamente deber indagar únicamente en el contexto de lo escrito, lo que implica la letra y la intención del legislador. VAlencia (1987) Tomo I, p. 48 y ss; por ejemplo, sostiene que tiene como propósito identificar los términos lingüísticos de la norma a interpretar con el grupo gramatical de las normas relacionadas. La referencia necesaria de este viraje, tiene su razón además, en el cambio de ideología política que sirve a cada uno, en tanto, el método literal, y genético surgen históricamente en torno a unos intereses capitalistas que surgieron de la mano con la revolución francesa propugnando por sobre todo, por la previsibilidad de las decisiones de los jueces en concreción del principio democrático, para de esa manera evitar que estos interpretaran, la ley a su arbitrio, e impusieran la voluntad diferente a la
} 
tico $^{7}$, a uno teleológico ${ }^{8}$ o sistemático-finalista. Bajo este esquema, y de acuerdo con López Medina, "la aplicación formalista del texto debe ceder ante el propósito cuando, por alguna circunstancia, el texto parezca llevar a resultados contrarios a los que conduciría el fin normativo" de esa manera "el fin o propósito no se encuentra en la intención, sino en una reconstrucción plausible de los fines permisibles y legítimos que las normas deben cumplir en las nuevas circunstancias"10. De acuerdo con Alexy, la aplicación de este método "se caracteriza porque quien argumenta se refiere no a fines de personas realmente existentes en el pasado o en el presente, sino más bien a fines racionales o prescritos objetivamente en el contexto del ordenamiento jurídico vigente" ${ }^{11}$. Este método supone necesariamente apelar a los fines o causalidad de la ley ${ }^{12}$, se trata de fines sociales que el intérprete debe descubrir, "para lo cual se inspirará en el sentido de la hora presente y en el sentido político, es decir en la comprensión de los valores de la comunidad"13.

Así y teniendo en cuenta que la integridad es cuestión de principios; y que los principios son reglas generales que pueden expandirse y contraerse en forma orgánica, y responder a las necesidades de los individuos que hacen parte de la sociedad sin la necesidad de una legislación detallada e inclusive sin adjudicación en cada punto de posible conflicto -que además hacen parte de una red que supedita la coherencia de las decisiones, en tanto se respeten los principios-, se requiere necesariamente identificarlos, debido a que la interpretación de la ley depende de ellos.

La concepción de integridad desde la óptica de la adjudicación impone que "los jueces deben concebir el cuerpo de la ley que administran como una totalidad y no como un conjunto de decisiones discretas que se pueden tomar o enmendar una por una, sin nada más que un interés estratégico en el resto" ${ }^{14}$. Así pues, observar el derecho desde este principio adjudicativo de integridad se puede considerar como una teoría que le permite al juez interpretar las normas desde la mejor perspectiva posible, siendo más cuidadoso, imaginativo y amplio en su búsqueda de los principios y valores que le subyacen ${ }^{15}$.

del legislador. ManRiQue (2014) p. 125 y ss; Así, tal y como lo establece Calvo (1994) p. 68: "La escuela de la exégesis envuelve el principio político de la división de poderes, el principio constitucional básico de las nuevas democracias liberales, y el principio de legalidad sobre el que descansa la legitimación del ejercicio del poder administrativo y judicial".

7 Para AleXy (2007) p. 229; el argumento genético atiende a la voluntad del legislador, o los fines que persiguió el legislador.

${ }^{8}$ AleXY (2007) p. 231: En su teoría de la argumentación jurídica se refiere al argumento teleológico indicando que el mismo "presupone un análisis detallado de los conceptos de fin y de medio, así como de los conceptos vinculados a éstos de voluntad, intención necesidad práctica y fin". Lo subdivide en argumentos teleológicossubjetivos y objetivos. A la primera definición se acerca desde nuestro parecer al argumento genético, indicando que éste se relaciona con las finalidades previstas por el legislador, los segundos y al que nosotros nos referimos como teleológico o finalista.

9 López (2006) p. 36.

10 LÓPez (2006) p. 38.

11 Alexy (2007) p. 232.

12 Manrique (2014) p. 310.

13 Isaza (2020) p. 86.

${ }_{14}$ Dworkin (1986) p. 125.

15 Dworkin (1988) p. 161. 
Teniendo en cuenta lo antes mencionado, la interpretación y comprensión del derecho en este escenario cambia, de manera que no puede solamente realizarse desde el ámbito legal. También debe existir una amalgama con lo constitucional, en la medida que en la constitución ya no solo existen criterios negativos en cuanto limitaciones de la función del estado en torno a la restricción de las libertades del individuo sino que además se establecen criterios positivos, en tanto obligaciones del estado para garantizar, ejecutar y concretar los derechos (del individuo) en su relación con el estado, y las diversas a este. Esto conlleva que la constitución se proyecte hacía las relaciones entre particulares de manera que no opera de manera vertical regulando relaciones entre el Estado y el individuo, bajo el binomio libertad-autoridad; y a su vez opera de manera horizontal, regulando relaciones en las que no interviene el estado, como puede ser individuo-individuo ${ }^{16}$.

La segunda visión de la integridad desde la visión de Dworkin ${ }^{17}$, se equipara con la idea de moralidad personal, y apunta al intérprete, invitándolo a convertirse en una persona moral íntegra cuyo actuar es recto e intachable. De esta manera se debe analizar el derecho como un conjunto en donde no solo existen proposiciones normativas dentro del ordenamiento jurídico sino también principios coherentes y directrices políticas que justifican o dan sentido a aquellas reglas. La visión del derecho como integridad de Dworkin implica que el intérprete de la obra conciba a las normas jurídicas como el resultado de las convicciones y los valores que han marcado a una determinada comunidad política a partir de lo que aquella ha vivido. Por ello, los jueces al momento de aplicar el derecho, se encuentran compelidos a interpretar el contenido tanto explícito como implícito que se encuentran condensados en estos preceptos para poder construir la mejor interpretación posible. Lo anterior supone comprender que dentro de su capacidad interpretativa, el juez deba asumir una actitud de respeto frente a la integridad del ordenamiento jurídico para optar siempre por elegir la interpretación más correcta o acertada. De allí que se conciba a la integridad como un valor o ideal en sí mismo que debe estar subordinado a los demás.

En este punto sostiene Dworkin ${ }^{18}$ que las interpretaciones son estados de preferencias que necesariamente deben ser una proyección de aquello que se considera lo mejor posible y que por lo tanto permite alcanzar el éxito. Esta idea de interpretación parte del presupuesto del entendimiento de que cuando se interpreta se busca alcanzar el éxito, de manera que la interpretación que se realice debe necesariamente considerarse es la mejor para alcanzar a cumplir determinados objetivos que se representan en los valores subyacentes a las reglas interpretadas. Esta visión de integridad se parece mucho a la idea desarrollada por Finnis ${ }^{19}$, sobre la razonabilidad práctica, claro, sin aglutinar en su idea, sus requerimientos ${ }^{20}$. Desde esta visión el juez cuando elige entre alternativas interpretativas debe

\footnotetext{
16 Esta característica la denomina ZAGREBELSKY (2008) p. 81 como eficacia directa horizontal.

17 DWORKIN (1988) p. 125.

18 DWORKIN (2014) p. 190 y ss.

19 Finnis (2011) p. 100 y ss.

FinNis (2011) p. 190 y ss.

20 FinNis (2011) p. 100 y ss. plantea una categoría de lo razonable que se adquiere luego de cumplir con unas exigencias, que se alcanzan al respetar una metodología de sujeción a 7 principios que él denomina como: bienes básicos, y 9 exigencias de la razonabilidad práctica.
} 
responder a interrogantes como: ¿Qué es lo que quiero para mi vida?, ¿Qué quiero para la vida de los demás?, ¿Qué quiero para el sistema? Al responder esos interrogantes, no puedo querer para mi vida, nada distinto de lo que querría para los demás, de manera que mi plan de vida como individuo, debe acoplarse con el sistema y la sociedad.

\section{CONTORNOS MÁS CONCRETOS A LA NOCIÓN DE INTEGRIDAD Y SU ACERCAMIENTO A LA NOCIÓN DE COHERENCIA}

Las grandes críticas que se enarbolan contra la propuesta de Dworkin, radican entre otras, en la falta de concreción de sus tesis y en últimas, lo abstracto de sus propuestas. Trataremos en las líneas que siguen, en suplir esas deficiencias. Así, desde la primera visión que anunciamos, la manera de concretar la noción de integridad es relacionándola con la de coherencia. Al hacer esto, le damos un contenido lógico a la noción holista de interpretación, y con ello apropiamos como herramienta para las decisiones, las inferencias o conexiones lógicas entre las reglas del sistema. Tengamos en cuenta que la coherencia, llamada por MacCormick ${ }^{21}$ como "consistencia", es una propiedad lógica y de pertenencia de reglas al sistema, requisito que se satisface cuando la decisión "se basa en premisas normativas que no entran en contradicción con normas válidamente establecidas" ${ }^{22}$. Pérez Bermejo ${ }^{23}$ la desglosa en 3 exigencias: (i) Consistencia local; (ii) Interconexión; y (iii) Unidad.

La Consistencia local, se refiere a una determinada área del sistema ${ }^{24}$. Se aplica la consistencia local en una decisión cuando se busca encajar la interpretación en un área, o materia específica del sistema. La interconexión busca encontrar la mayor cantidad de inferencias o conexiones lógicas posibles, de manera que pueda hablarse de una red como un tejido tupido que se proporcione apoyo recíproco. Es algo así como la existencia de los respaldos que apoyen una determinada regla. Desde esta perspectiva, cuando se trata de lograr esta interconexión, se busca apoyo de una decisión en la mayor cantidad de principios. El tercer criterio es la unidad, que supone elegir aquella interpretación que responda de mejor manera al sistema en conjunto, evitando el desorden, y las contradicciones.

Para ilustrar esta noción de coherencia, pensemos en el sistema como un conjunto de círculos que se conectan con la ayuda de una espiral. Cada círculo constituirá un área del sistema. Por ejemplo, el derecho civil, el comercial, el procesal civil, el constitucional. El espiral tiene la función de interconectar las unidades más pequeñas con las más grandes, para lograr que exista una unidad. El juez al decidir, debe iniciar siempre por las unidades locales que representen el área específica de estudio y explorar todas las posibilidades decisorias en las restantes unidades hasta llegar a la constitución. Lo anterior puede representarse con la siguiente imagen:

${ }^{21}$ MacCormick (1978) p. 129 y ss.

22 Atienza (2005) p. 117.

23 Pérez Bermejo (2015) pp. 191-193.

24 Para Mendonca (2008) p. 173; la noción de sistema normativo consiste en lo sustancial, "en la posibilidad que existe de determinar las soluciones jurídicas para una materia dada, de extensión variable pero siempre limitada”. El sistema normativo así, será aquel que correlacione consecuencias (soluciones) con diferentes situaciones (casos). 

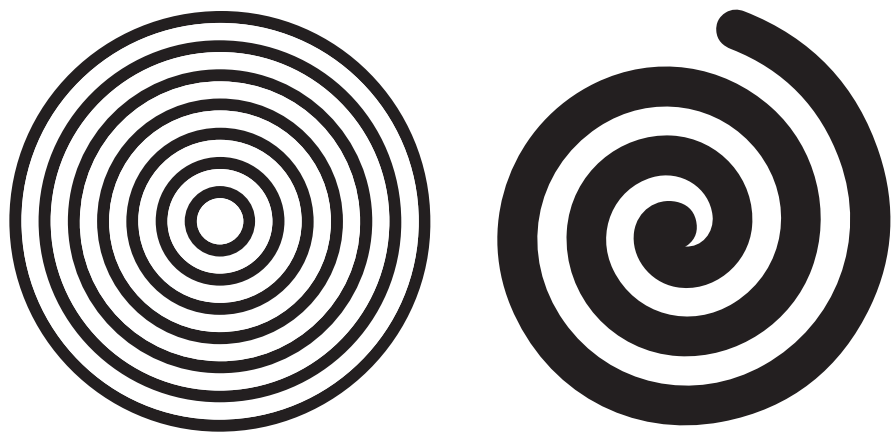

Pensemos por ejemplo que voy a decidir sobre el mérito probatorio de un contrato que ha sido falsificado, y que la decisión debe tomarla un juez de la especialidad civil. Al decidir, debo explorar posibilidades decisorias no solo del proceso civil, además, del código civil, del código penal, del código de procedimiento penal, y finalmente de la constitución. Luego de ello tendré una serie de posibilidades decisorias sobre las cuales debo elegir. La consistencia tiene como propósito permitirle al decisor, explorar e identificar todas las posibilidades decisorias.

En este escenario la jurisprudencia cumple un papel relevante al identificarse en ella muchas conexiones lógicas, y sobre todo responder al principio de equidad. No significa que sea el único criterio, pues muy a pesar de que puedan existir respuestas en el precedente, siempre debe tenerse en cuenta la segunda dimensión anunciada, tal y como lo veremos.

La segunda dimensión anunciada del concepto de integridad es la ética. Desde esta dimensión, el juez debe elegir de entre las posibilidades decisorias aquella que en mayor medida responda al valor de la justicia. Tengamos en cuenta que la integridad aspira a la equidad, pero también a la justicia material. Es decir, a que se resuelvan los problemas como en el pasado, pero también a abrir la puerta a decisiones distintas, siempre que ellas propicien alcanzar el postulado de justicia material, teniendo en cuenta que a veces la decisión más justa no es la más consistente.

Es muy extenso hablar de una teoría de la justicia en Dworkin, en tanto se trata de uno de los temas más desarrollados en sus obras. Nosotros en aras de plantear una metodología decisional del juez Hércules, pensaríamos que este luego de cumplida la primera dimensión, deberá siempre preguntarse ¿Cuál de las posibles decisiones es justa? Este planteamiento nos acerca a la aporía fundamental que plantea Viehweg ${ }^{25}$, y aun cuando sigue siendo muy genérico, constituye un buen punto de referencia.

Pues bien, la respuesta a la pregunta estará delimitada por compromisos personales, y la responsabilidad que asumimos ante ellos, teniendo en cuenta, además, que las decisiones que toma el juez, como individuo tienen una incidencia política ${ }^{26}$. Al llevar a un plano político las decisiones se impone la obligación al juez el deber de decidir como lo haría el legislador (no solo el tribunal constitucional, cualquier juez que interprete la constitución

\footnotetext{
25 VieHWEG (2007) p. 56 y ss.

26 DWORKIN (1988) p. 140.
} 
en virtud de la noción de integridad) y por ende, debe velar por garantizar el beneficio de la comunidad. Este beneficio, se analiza desde la visión democrática desarrollada por Dworkin, quien considera que no se trata de una decisión de mayorías, sino de una decisión asociativa que supone la defensa de los intereses de cada ciudadano ${ }^{27}$, intereses que se definen en caso de desacuerdo, no tomando en cuenta la mayor cantidad que apoyen la una o la otra, sino las razones que se utilizan para apoyarlas. Por lo tanto, la razón que deba elegirse, se define a partir de argumentos.

Esta razón definitoria será elegida por las convicciones de quien decide, y al final, será una cuestión concretada en lo que se considera debe ser lo mejor, y lo será aquella que convierta al derecho en la mejor realización comunicativa posible, que en palabras de Dworkin $^{28}$, responden a aquella refleje a la comunidad desde una mejor perspectiva. Se trata de una decisión dialógica, que toma en cuenta los intereses en conflicto para buscar un punto con el que ambos estén comprometidos, teniendo como referencia siempre, el interés general. La manera más concreta que explica Dworkin ${ }^{29}$ referente a esa decisión la denomina pragmatismo jurídico, y supone que el juez al decidir deba mirar al futuro, identificando las consecuencias de las decisiones, eligiendo la que genere mayor bienestar o que logre maximizar en mayor medida los intereses de la población. Se trata de una manera de decidir a partir de consecuencias.

\section{IMPORTANCIA DE UN MODELO ARGUMENTATIVO QUE UTILICE LA INTEGRIDAD Y COHERENCIA}

Tengamos en cuenta que en Colombia, la Constitución de 1991 que actualmente rige, supuso un viraje en torno a la estructura del Estado y su relación con los particulares, pues comenzamos a hablar de categorías normativas extrañas a la Constitución de 1886, tales como los derechos fundamentales, y con ello lo que Alexy llama o denomina "el efecto de irradiación" ${ }^{30}$. Esta noción supone entender que los principios iusfundamentales son supremos e influyen en todo el sistema jurídico. Apareció de la mano con esta nueva filosofía, un tribunal constitucional encargado de ser el guarda del nuevo modelo, con los poderes suficientes para hacer valer o privilegiar aquellas interpretaciones que respondieran a ella, expulsando del sistema las que lo contradiga ${ }^{31}$.

\footnotetext{
27 DWORKIN (2008) p. 168.

28 DWORKIN (1988) p. 185.

29 DWORKIN (2007) p. 31 y ss.

30 Para AleXy (2012) p. 507; las normas iusfundamentales contienen no solo derechos subjetivos de defensa del individuo frente al Estado, sino que representan, al mismo tiempo, un orden valorativo objetivo que, en tanto decisión básica jurídico constitucional, vale para todos los ámbitos del derecho y proporciona directrices e impulsos para la legislación, la administración y la justicia.

31 La Corte Constitucional Colombiana de acuerdo con el artículo 241 de la Constitución Política de 1991, tiene como funciones: Numeral 4. "Decidir sobre las demandas de inconstitucionalidad que presenten los ciudadanos contra las leyes, tanto por su contenido material como por vicios de procedimiento en su formación".
} 
Esta visión del sistema irradiado por principios implica necesariamente la existencia de una red $^{32}$ que se entrelaza entre lo legal y lo constitucional, conllevando que se convierta el derecho en lo que Dworkin conoce como una práctica interpretativa ${ }^{33}$ que solo puede entenderse a partir de la noción de integridad y coherencia, lo que por contera supone que el sistema sea la conjunción entre lo sucedido por la jurisprudencia, la ley y los principios constitucionales. Lo anterior justifica la posibilidad de aplicar la metodología del juez Hércules al momento de decidir, y garantizar a partir de ella, resultados favorables. Permite esta nueva visión ayudar a solucionar los problemas por existencia de antinomias ${ }^{34}$ y lagunas axiológicas ${ }^{35}$.

Insistimos en que se quiere mostrar es una metodología de interpretación que asume como presupuestos las nociones de novela en cadena, las de integridad y coherencia. Para describir la manera en que consideramos debe aplicarse, reconstruiremos el debate que se anunció al inicio, y que gira respecto a las dos interpretaciones posibles frente al artículo 121 del CGP.

\section{RECONSTRUCCIÓN DE LA DISCUSIÓN PLANTEADA POR LA JURISPRUDENCIA COLOMBIANA EN TORNO A LA APLICACIÓN DEL ARTÍCULO 121 DEL CGP}

En Colombia a partir de la entrada en vigor del Código General del Proceso (Ley 1564 de 2012), se llevó a cabo un viraje en la filosofía que se cimentó a partir del precepto contemplado en el artículo $11^{36}$ del estatuto procesal, el cual quiso constitucionalizar el

\footnotetext{
32 Para Ost y Van de Kerchove (2018) La validez de un sistema no puede verse ya, simplemente desde la perspectiva piramidal que explicaba en su momento Kelsen (2013); y que hacía depender la validez del sistema de una norma fundante básica no puesta, sino supuesta o presupuesta, que supeditaba la validez del sistema al procedimiento de creación contenido en la constitución; más allá lo supedita a dos elementos adicionales: la efectividad o validez fáctica, y la legitimidad o validez axiológica. Sobre la primera Ost y VAN DE KERChOve (2018) p. 354; sostienen que ella se entiende como "la capacidad de la norma para orientar el comportamiento de sus destinatarios en el sentido deseado por el legislador", pero que además comprenda tanto los efectos previstos e imprevistos teniendo siempre en cuenta que con ella se deba alcanzar el objetivo esperado, y evitar resultados simbólicos lo que solo se logra dando una mirada en la sociedad y los efectos producidos por la norma. La legitimidad por su parte la describen como aquel criterio "que pretende apreciar la validez de los actos y normas jurídicas bajo el rasero de valores metapositivos": OST y VAN DE KERCHOVE (2018) p. 362.

33 DWORKIN (1988) p. 164.

34 Para Moreso y Vilajosana (2004) p. 105; las antinomias por su parte surgen cuando un caso tiene, o está correlacionado con al menos dos soluciones incompatibles entre sí.

35 Según Alchourrón y Bulygin (2013) p. 156; existen lagunas normativas y lagunas axiológicas, indicando que las primeras surgen por la falta de solución en el sistema; las segundas surgen en aquellos sistemas que si bien existen soluciones "la solución existente es axiológicamente inadecuada". De esa manera, en las lagunas axiológicas, el caso tiene una solución (de lo contrario será una laguna normativa) posible en el sistema, sin embargo, una vez llevada a cabo la interpretación de la fuente, y una vez realizado el proceso de normativización, encontramos que la misma es contradictoria con el conjunto de valores, intereses y principios que conforman el sistema.

36 LEY No 1564 de 2012, Art. 11. Interpretación de las normas procesales "Al interpretar la ley procesal el juez deberá tener en cuenta que el objeto de los procedimientos es la efectividad de los derechos reconocidos por la ley sustancial. Las dudas que surjan en la interpretación de las normas del presente código deberán aclararse mediante la aplicación de los principios constitucionales y generales del derecho procesal garantizando en todo caso el debido proceso, el derecho de defensa, la igualdad de las partes y los demás derechos constitucionales fundamentales. El juez se abstendrá de exigir y de cumplir formalidades innecesarias".
} 
proceso para dar prelación al derecho sustancial sobre las formas, concretando de esa manera el mandato contenido en el canon 228 constitucional ${ }^{37}$. Dentro de las consecuencias prácticas que se generaron con esta disposición fue cambiar la visión del proceso a aquella que no lo viera como receptor de derechos fundamentales, sino que buscara la defensa de los sujetos que se encuentran inmersos en él; por ende, se flexibilizan los trámites, implicando que no exista vulneración de derechos del proceso, sino vulneración de derechos de los sujetos procesales, de manera que el proceso ya no será un fin en sí mismo sino un medio para un determinado $\mathrm{fin}^{38}$.

Con todo esto, se quiso presentar un estatuto con un elevado grado de coherencia interna $^{39}$ en orden a priorizar el derecho sustancial; empero, ello no fue del todo así, pues se presentaron contradicciones entre esa filosofía diseñada para caracterizarse por su flexibilidad, con interpretaciones que convertían al proceso en un receptor de derechos fundamentales y a la vez sostenían que la violación a trámites previstos en él, implicaran per se vicios que no podrían ser saneados.

La discusión puntual que queremos advertir surgió en torno a la llamada nulidad de pleno derecho contemplada en el artículo 121. La figura tenía como propósito ponerle fin a la problemática de la mora judicial en el país, fijando un límite máximo de un año para proferir sentencia de primera instancia en aras de garantizar la tutela judicial efectiva ${ }^{40}$, contemplando en los eventos que no se respetara, una consecuencia jurídica consistente en una sanción procesal de pérdida de competencia del funcionario judicial y la nulidad insaneable de todas las actuaciones que fueren proferidas con posterioridad a dicho lapso, inclusive, la sentencia.

Frente a esta llamada nulidad de pleno derecho se ventilaban 2 posiciones: (i) una que la consideraba contradictoria a la filosofía del nuevo estatuto procesal; y (ii) otra que la consideraba acorde a ella. A la postre la discusión fue zanjada por una decisión de la Corte Constitucional, en la que asumió la primera postura.

En las líneas que siguen reconstruiremos la discusión que se generó en la jurisprudencia colombiana, haciendo especialmente énfasis en las razones fundamentales esgrimidas en las decisiones, para a la postre justificar la manera en cómo la Corte Constitucional llevó a cabo una metodología argumentativa propia del juez Hércules. Con esto se busca mostrar, cómo se aterriza la propuesta argumentativa en la práctica, haciendo para ello un recorrido en las decisiones erradas tomadas por las Cortes que conforman la jurisdicción

37 Para Tejeiro (2017) pp. 1-32; el nuevo estatuto procesal incorpora como pilares los principios de informalidad y elasticidad, el primero contemplado en el artículo 11, le prohíbe al juez exigir formalidades innecesarias, garantizando con ello erradicar la cultura del formalismo inútil; el segundo llamado también de flexibilidad legal le permite al juez manejar el proceso sin encuadramientos ni formulas férreas, exigiéndole al juez el uso del sentido común, el debido proceso, la razonabilidad y la proporcionalidad.

38 Esta filosofía es reconocida por la Corte Constitucional, entre otras, en las sentencias C-095 de 2001, C-316 de 2002, C-622 de 2004, C-086 de 2016.

39 ROJAS (2016) p. 19.

40 Chamorro (1994) p. 11: "Entiéndase por tutela judicial efectiva el derecho fundamental que toda persona tiene a la prestación jurisdiccional, es decir, a obtener una resolución fundada jurídicamente, normalmente sobre el fondo de la cuestión que, en el ejercicio de sus derechos e intereses legítimos, haya planteado ante los órganos judiciales". 
ordinaria, hasta llegar a la decisión tomada por la Corte Constitucional, donde declaró inconstitucional un artículo del código procesal civil vigente, que fue recurrentemente interpretado de manera indebida y que a la postre generó toda la controversia estudiada.

\section{ANÁLISIS DE LAS DECISIONES EMITIDAS EN TORNO A LA INTERPRETACIÓN DEL ARTÍCULO 121 DEL CÓDIGO GENERAL DEL PROCESO}

\section{1) Sentencias de la Corte Suprema de Justicia}

La Corte Suprema de Justicia ${ }^{41}$ en sus diferentes salas, es la máxima autoridad judicial en materia civil, penal y laboral. El primer pronunciamiento que realizó sobre el tema se encuentra en la Sentencia 8849 del año $2018^{42}$ en donde se decidió sobre la impugnación del fallo proferido por la Sala Civil del Tribunal Superior del Distrito Judicial de Cali dentro de la acción de tutela promovida por Hernán Quezada contra los juzgados Tercero Civil Municipal y Noveno del Circuito, a través de la cual pretendía la invalidez de todo lo actuado dentro del proceso declarativo que había promovido el accionante contra la empresa Allianz Seguro S.A pues según él los falladores de instancia, habían incurrido en un defecto sustantivo. El ad quo al seguir conociendo del proceso cuando había perdido competencia en virtud del artículo 121 del C.G.P. y el ad quem por interpretar de manera errónea tal nulidad, aduciendo que aquella aunque era de pleno derecho, resultaba saneable.

En las consideraciones de esta providencia la CSJ manifestó que los jueces de instancia cometieron un desafuero al desconocer lo reglado por el artículo 121 del Código General del Proceso e incluir una salvedad que no estaba regulada legalmente, vulnerando así el debido proceso del accionante pues el plazo para dictar sentencia contemplado por la norma procesal corre de forma objetiva y por ende la nulidad que allí se establece opera de "pleno derecho", es decir, no le es aplicable el principio de invalidación o saneamiento porque esto contradiría el querer del legislador de imponer a los jueces la obligación de dictar sentencia en un lapso perentorio.

La Corte interpretó como principio subyacente para amparar su decisión, el de celeridad, pues se consideró que la nulidad prevista como sanción procesal por el artículo 121 del C.G.P debía ser entendida desde la finalidad objetiva que la norma persigue, esto es, la estipulación de plazos perentorios para la resolución de los litigios. Se hace referencia a que la intención del legislador era establecer la obligación en los operadores de justicia de dictar sentencia en un determinado tiempo, sin tener en cuenta las circunstancias o cambio alguno que puedan surgir en el ejercicio de aplicación de la administración de justicia e incluso en la realidad del país, mostrando un criterio interpretativo genético ${ }^{43}$, que denota sobre

\footnotetext{
41 En adelante CSJ.

42 Corte Suprema De Justicia, Sala De Casación Civil (11 de julio de 2018) Stc8849-2018 [Mp. Aroldo Wilson Quiroz Monsalvo].

43 Para AleXY (2007) p. 229; el argumento genético atiende a la voluntad del legislador, o los fines que persiguió el legislador. La voluntad del legislador es solo una razón para una interpretación. Incluyen enunciados sobre la voluntad del legislador. Para aplicarlos se expresa "que una determinada interpretación expresa el tenor de la norma, la voluntad del legislador o el fin de la norma".
} 
todo un ideal apegado a la escuela de la exégesis ${ }^{44}$. Se advierte que la interpretación utilizada mira únicamente en el microsistema normativo del estatuto procesal civil, por lo que en términos dworkinianos, puede decirse que solo utilizó a una consistencia local.

La Sentencia 14822 del año $2018^{45}$ resolvió en segunda instancia la acción de tutela instaurada por Transportes Armenia S.A. en contra de la Sala Civil del Tribunal Superior del Distrito Judicial de Bogotá solicitando dejar sin efectos la providencia proferida por ese cuerpo colegiado. Adujo el solicitante que la decisión había desconocido el precedente jurisprudencial proferido por la CSJ, al haberse tenido en cuenta lo manifestado en la sentencia de la Corte Constitucional T-341 de 2018 en donde se establece la posibilidad de ser saneable la nulidad de pleno derecho contenida en la norma en mención, porque se trataba de un pronunciamiento con efectos inter partes y no inter comunis.

La CSJ en esta sentencia reiteró la hermenéutica de interpretación que fue en principio plasmada en la Sentencia 8849-2018, consistente en que el anotado plazo de la norma procesal para dictar sentencia corre de forma objetiva, salvo interrupción o suspensión del litigio, sin que esta postura fuera cambiada por lo mencionado en la jurisprudencia constitucional (Sentencia T-341/18). Además, consideró que el juez de primera instancia erró en su decisión al establecer una nueva salvedad a la norma consistente en que se había saneado la nulidad porque ninguna de las partes alegó la pérdida de competencia de la autoridad con anterioridad al fallo de primer grado, situación que no contemplaba la norma. Como vemos, en esta providencia la CSJ justifica su sentencia basada simplemente en el principio de equidad, que es un presupuesto lógico de la coherencia, pero que de la manera en que se utilizó, olvida hacer cualquier razonamiento sobre criterios de justicia material, dejando de lado la dimensión ética que debe tener en cuenta el juez al decidir.

La Sala Laboral de la CSJ, a través de la sentencia 3703 de $2019^{46}$ decide sobre la impugnación formulada por la Sala de Gobierno del Tribunal Superior del Distrito Judicial de Cundinamarca contra el fallo proferido por la Sala de Casación Civil en el trámite de la tutela que promovió José Arturo Mórtigo Pinzón en contra de un Juzgado Civil del Circuito de Funza. El accionante presentó demanda de prescripción extintiva de acción cambiaria y cancelación de hipoteca en contra del Banco Av. Villas, pretensiones que fueron resueltas de manera favorable por el juzgado promiscuo municipal de Cota y cuya decisión fue objeto de recurso de apelación por parte del demandado. En virtud de ello el proceso fue remitido al juzgado civil del Circuito de Funza, despacho que declaró la nulidad de pleno

\footnotetext{
44 Para la escuela de la exégesis la completud y racionalidad a priori - de la ley, se basada en la idea de un legislador racional y sabio, que se arropaba con un manto de divinidad, producto de la creencia influenciada por el iusnaturalismo teológico medieval según la cual, la ley se conformaba por el contenido del querer de Dios, conllevando a que el juez como aplicador del derecho, debiera atenerse al sentido literal de lo establecido en ella. Sostiene Solano (2016) p. 171: "Esta escuela, que tuvo su origen en Francia con la codificación napoleónica, se soportó en el llamado "mito del legislador racional”; la expresión "exégesis" tiene su origen en la hermenéutica de los textos sagrados; exégesis es, precisamente, interpretación de los textos sagrados. La función del intérprete consiste en descubrir la voluntad del legislador, quien es una "mina inagotable de sabiduría jurídica", a partir de la literalidad del texto".

45 Corte Suprema De Justicia, Sala De Casación Civil. (14 de noviembre de 2018) Sentencia 148222018/2018-02896 [Mp. Aroldo Wilson Quiroz Monsalvo].

46 Corte Suprema De Justicia, Sala Laboral. (13 de marzo de 2019) Stl3703-2019. [Mp. Castillo Cadena, Fernando].
} 
derecho de todo lo actuado al considerar que se había materializado la falta de competencia del despacho según lo establecido en el artículo 121 del Código General del Proceso. El tribunal accionado desestimó la falta de competencia y devolvió el proceso al juzgado Civil del Circuito de Funza manifestando que el término previsto en el artículo 121 del Código General del Proceso para decidir en segunda instancia sobre el asunto no había transcurrido, teniendo en cuenta que el nuevo juez se había posesionado recientemente y por razones hermenéuticas en caso de cambio de titular del despacho judicial debe computarse el término nuevamente a partir de que el funcionario ha entrado a ocupar el cargo.

Teniendo en cuenta los hechos antes mencionados, la sala laboral de la CSJ planteó como problema jurídico determinar si el cambio de funcionario de conocimiento del proceso justificaba un nuevo conteo del término establecido en el artículo 121 del CGP, pues la norma no precisa sobre aquellas circunstancias particulares que pueden presentarse en el curso de un proceso, como acontece en este caso, sobre el cambio de juez del despacho; evidenciándose así un vacío legal. Frente al problema jurídico planteado la Sala consideró que el tribunal no incurrió en ninguna vulneración de los derechos fundamentales del accionante pues las razones para no declarar la nulidad se debieron a las circunstancias particulares del caso como lo fue el cambio de funcionario de conocimiento del proceso. Se apoyó en la tesis de la Corte Constitucional (Sentencia T-341 de 2018), precisando que era necesario flexibilizar la nulidad de pleno derecho, siempre y cuando se respete la garantía del plazo razonable; teniendo en cuenta que las nulidades procesales son una medida de última ratio debido a los efectos adversos que ella genera para los usuarios de la administración de justicia y que repercute en una mayor demora en resolver los procesos a su cargo.

Esta última decisión no asumió idéntica postura a la de los pronunciamientos previamente reseñados ${ }^{47}$, ( 2 de la CSJ y 1 de la Corte Constitucional) aún así, se mostraron simpatizantes a la tesis de la comisión redactora desarrollada por la Sala de Casación Civil, sin embargo se distanciaban de aquella en su noción de coherencia, en la medida que no se limitaron a identificar relaciones lógicas y una solución interpretativa basada en un criterio de autointegración ${ }^{48}$ o consistencia local que denomina Dworkin, más allá acogieron un criterio de interpretación que atendía las diversas circunstancias que pueden acontecer en el desarrollo del proceso, lo que se acompasa con la dimensión ética a la que hicimos referencia.

Finalmente, la Sala de Casación Civil de la CSJ en la Sentencia 12660 de $2019^{49}$ expone una nueva consideración respecto del término para dictar sentencia contemplado en el artículo 121 del C.G.P, manifestando que este no corre de forma objetiva, sino que por su naturaleza subjetiva ha de consultar realidades de cada proceso; como el cambio de titularidad de un despacho vacante. Sostuvo la CSJ que en el caso de que un nuevo funcionario tomara posesión como juez o magistrado de un despacho judicial se reiniciará el cómputo del término de duración del plazo razonable señalado en la norma procesal.

\footnotetext{
47 Ver: Sentencia 8849 (2018), Sentencia 14828 (2018), Sentencia 14507 (2018).

48 Para Bоввіо (1992) pp. 230-231. La integración normativa puede ser de dos tipos: la Auto integración y la Heterointegración. La primera hace referencia aquellos casos en los que las lagunas se superan utilizando reglas de la misma legislación. La segunda se supera a partir de otra ley o a una fuente de naturaleza extralegal, es decir los principios.

49 Sala De Casación Civil. (18 de septiembre de 2019) Sentencia 12660-2019. [Mp. Luis Alonso Rico Puerta].
} 
Sin embargo, el magistrado Aroldo Wilson Quiroz Monsalvo se apartó de dicha decisión y salvó su voto, pues no compartía el carácter subjetivo que se le dio al término previsto en la norma, para él la Corporación se apartó del reiterado precedente que desde el 11 de julio de 2018 había venido construyendo la Sala acerca de "la forma en que debe implementarse una política pública dirigida a solucionar la mora judicial como uno de los principales problemas que enfrenta la administración de justicia colombiana”. Manifestó que el fenómeno de la mora judicial es un problema estructural (no coyuntural) de nuestra Nación, que amerita soluciones basilares basadas en políticas públicas como la incorporada, precisamente, por el artículo 121 del Código General del Proceso, fundada en la objetividad del término de duración de los trámites y la nulidad de pleno derecho de las actuaciones tardías.

\section{2) Sentencias de la Corte Constitucional}

Por su parte y contrario al análisis desarrollado por la CSJ, la Corte Constitucional de Colombia en la Sentencia T-341 de 2018 ${ }^{50}$, abordó la revisión del fallo de segunda instancia en el proceso de tutela promovido por Sandra Agudelo contra el Juzgado Segundo Civil del Circuito de Fusagasugá y el Tribunal Superior del Distrito Judicial de Cundinamarca Sala Civil Familia; adujo la accionante que se le vulneró su derecho fundamental al debido proceso, señalando que aun cuando en primera instancia se había dictado sentencia, el Tribunal de segunda instancia declaró la nulidad de lo actuado, sosteniendo que la sentencia de primera instancia se dictó por fuera del término previsto en el artículo 121 del Código General del Proceso. El problema jurídico sustancial que resolvió la Corte Constitucional a través de esta providencia fue determinar si existió defecto orgánico por la presunta pérdida de competencia de la primera instancia como resultado de la violación al término establecido por el artículo 121 del Código General del Proceso, y si en efecto, por tal irregularidad se deben anular todas las actuaciones que fueren surtidas con posterioridad a la impugnación resuelta por el tribunal en segunda instancia.

Al resolver el problema en cuestión, la Corte consideró que si bien el legislador fijó el término del juez para decidir, no debía únicamente este ceñirse al tenor literal, puesto que se conjugan diversos aspectos de relevancia constitucional que deben tenerse en cuenta al momento de construir un criterio hermenéutico, tales como la garantía del plazo razonable y el principio de lealtad procesal. En ese sentido y dentro del marco de tales garantías constitucionales, señaló que era posible que fuere convalidada la actuación judicial extemporánea, cuando lo que se busque sea la efectividad de los derechos reconocidos por la ley sustancial y la obtención de resultados normativos institucionales.

En la misma providencia, el máximo tribunal Constitucional identificó unas subreglas adicionales que incorporó al sentido literal de la disposición, señalando que los únicos eventos en que la actuación extemporánea del funcionario judicial no podrá ser convalidada y procedía la pérdida de competencia, eran los siguientes: “(i) Que la pérdida de competencia se alegue por cualquiera de las partes antes de que se profiera sentencia de

50 Corte Constitucional, Sala Primera De Revisión De Tutelas. (24 de agosto de 2018) Sentencia T-341 [Mp. Carlos Bernal Pulido]. 
primera o de segunda instancia, (ii) que el incumplimiento del plazo fijado no se encuentre justificado por causa legal de interrupción o suspensión del proceso; (iii) así mismo, que no exista prórroga de la competencia por la autoridad judicial; (iv) que la conducta de las partes no evidencie un uso desmedido, abusivo o dilatorio de los medios de defensa judicial durante el trámite de la instancia correspondiente; (v) que la sentencia de primera o segunda instancia, no se haya proferido en un plazo razonable”.

Por lo anterior, es claro que la construcción del criterio hermenéutico de interpretación de la Corte Constitucional, va más allá del sentido literal de la disposición y abre paso a una interpretación global del texto teniendo en cuentas las circunstancias de cada caso en concreto, los principios que rigen el ordenamiento jurídico y los fines prácticos de la administración de justicia.

Pero la discusión no acabó allí, en tanto, como se hizo ver el criterio acogido fue dubitativo, de manera que era unas veces acogido otras no. La definición del tema la realizó la Corte Constitucional en la sentencia T-443 de 2019, en ese momento al resolver una demanda de inconstitucionalidad promovida contra las reglas contenidas en el artículo 121 del Código General del Proceso. Al evaluar la constitucionalidad de la disposición, examinó en primer lugar, la finalidad con la cual el órgano legislativo diseñó la norma y segundo, teniendo en cuenta que la contribución a la eficacia y celeridad de la disposición es directa; el ejercicio analítico se encaminó a sopesar el aporte de la norma en la consecución de dicho objetivo frente al eventual sacrificio iusfundamental en términos de garantías procesales como el derecho al debido proceso y el derecho de acceso a la justicia.

Frente al anterior análisis, la Sala concluyó que la nulidad automática de las actuaciones procesales que se surten con posterioridad a la pérdida automática de competencia del funcionario judicial era una medida legislativa incompatible con la Constitución Política, pues además de no contribuir a la materialización de una justicia oportuna, resulta ser un obstáculo para lograr ese objetivo porque entorpece el desarrollo tanto de los trámites que se surten en la administración de justicia como el funcionamiento del sistema judicial como tal.

Sostuvo que la calificación "de pleno derecho" parece sugerir que la nulidad opera automáticamente y sin necesidad de declaración judicial, lo que en realidad abre un nuevo debate sobre la validez de las decisiones y de las actuaciones adelantadas por el juez que ha perdido la competencia, pero que, pese a lo anterior, ha dado continuidad al trámite judicial; anulando así otros principios sustantivos inherentes a la función jurisdiccional como el derecho a la resolución oportuna de las decisiones judiciales, el derecho de acceso a la administración de justicia, el derecho al debido proceso y la prevalencia del derecho sustancial.

Teniendo en cuenta los anteriores argumentos, se declaró la inexequibilidad de la expresión "de pleno derecho" contenida en el inciso 6 del artículo 121 del Código General del Proceso y la exequibilidad condicionada del resto del inciso, en el entendido de que la nulidad que se establece debe ser alegada por las partes antes de proferirse sentencia, esto es, cuando expiren los plazos establecidos por el artículo 121 del Código General del proceso para dictarla y que dicha nulidad es saneable en los términos del artículo 132 y subsiguientes del estatuto procesal. 


\section{A MANERA DE CONCLUSIÓN: LAS RAZONES POR LAS QUE CONSIDERAMOS QUE LA CORTE CONSTITUCIONAL APLICA LA METODOLOGÍA DEL JUEZ HÉRCULES DWORKINIANO}

Asumiremos que las decisiones del juez Hércules deben tener en cuenta (i) una dimensión de metodología jurídica y (ii) una dimensión ética. Podemos resumir la metodología anterior con el siguiente gráfico:

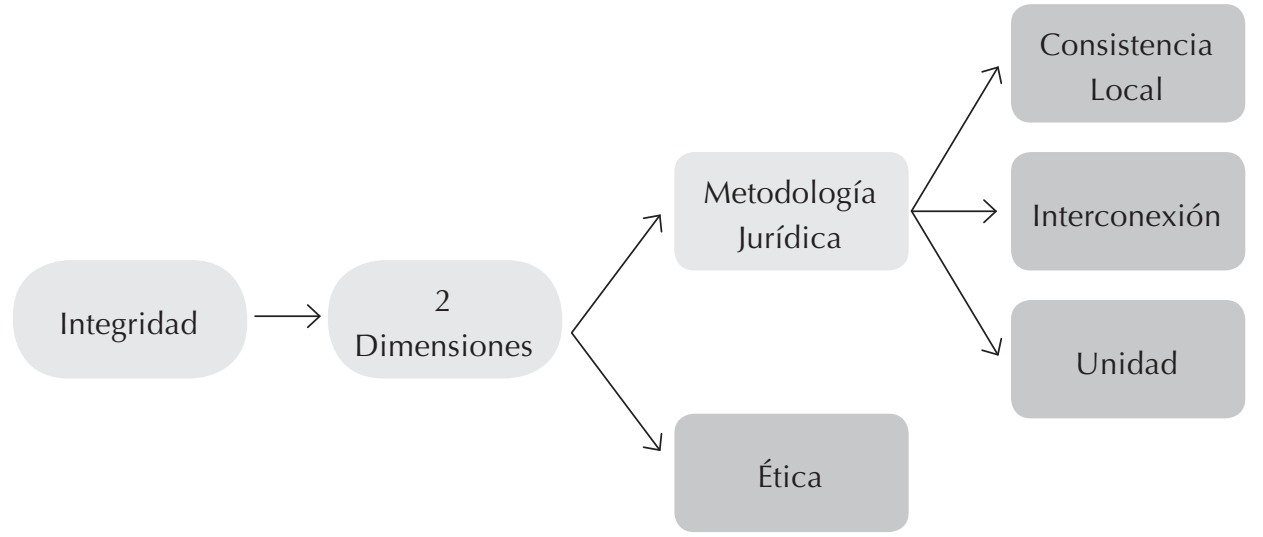

La dimensión (i) debe buscar relaciones lógicas tanto a nivel local, como a nivel externo y constitucional. Finalmente debe tomar en cuenta el precedente. Todo con el propósito de ubicar alternativas decisorias posibles. La dimensión (ii) debe analizar las alternativas posibles y escoger entre ellas, teniendo en cuenta la mejor interpretación posible. Para realizar esa elección analizará las razones que utilizan cada una, y escogerá la que mejor defienda los intereses de cada ciudadano. Cuando no pueda encontrar esos equilibrios de manera clara, proyectará su decisión en la sociedad, identificando las posibles consecuencias que tenga cada una en el entorno social, realizando una proyección al futuro, para determinar la que en sus efectos logre maximizar los intereses de la población.

\section{Metodología Juez Hércules}

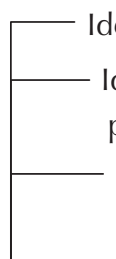

Identificar principios subyacentes a la interpretación.

Identificar conexiones lógicas entre la interpretación y los principios a nivel local.

- Identificar conexiones lógicas entre la interpretación y los principios en otras comunidades del sistema.

- Identificar conexiones lógicas entre la interpretación y los principios en la constitución.

- Identificar todas las interpretaciones posibles.

Escoger la interpretación que defienda los intereses de cada ciudadano.

Escoger la interpretación a partir de consecuencias. 
Güette Hernández, David M. / Rodríguez Cuadrado, Angie C. — "La forma como debe decidir el Juez Hércules..."

Teniendo en cuenta la metodología descrita, analizaremos las decisiones identificadas, que fueron las siguientes:

\begin{tabular}{|c|c|c|c|}
\hline RADICADO & SENTENCIA & CORPORACIÓN & SÍNTESIS DE LA DECISIÓN \\
\hline $\begin{array}{c}\text { 76001-22-03-000- } \\
\text { 2018-00070-01 }\end{array}$ & STC 8849-2018 & $\begin{array}{c}\text { Corte Suprema De } \\
\text { Justicia, Sala De } \\
\text { Casación Civil. }\end{array}$ & $\begin{array}{l}\text { La CSJ consideró que la nulidad } \\
\text { prevista en la norma debía ser } \\
\text { entendida de manera objetiva a } \\
\text { partir de la finalidad que con la } \\
\text { misma se persigue, consistente en la } \\
\text { imposición de un plazo razonable } \\
\text { para que los jueces dicten sentencia, } \\
\text { sin contemplar ningún tipo de } \\
\text { circunstancia que puedan surgir } \\
\text { en el ejercicio de aplicación de la } \\
\text { administración de justicia. }\end{array}$ \\
\hline $\begin{array}{c}11001-02-03-000- \\
2018-02896-00\end{array}$ & STC 14822-2018 & $\begin{array}{c}\text { Corte Suprema De } \\
\text { Justicia, Sala De } \\
\text { Casación Civil. }\end{array}$ & $\begin{array}{c}\text { Se reitera la hermenéutica de } \\
\text { interpretación que justifica que el } \\
\text { anotado plazo para dictar sentencia } \\
\text { previsto en la norma procesal corre } \\
\text { de forma objetiva, sin que puedan } \\
\text { alegarse salvedades que no han sido } \\
\text { previstas. }\end{array}$ \\
\hline T-6.708.920 & $\mathrm{T}-341-18$ & $\begin{array}{c}\text { Sala Primera } \\
\text { de Revisión } \\
\text { de la Corte } \\
\text { Constitucional. }\end{array}$ & $\begin{array}{l}\text { La Corte Constitucional determinó } \\
\text { que era posible que fuere } \\
\text { convalidada la actuación judicial } \\
\text { extemporánea del juez, cuando lo } \\
\text { que se busca sea la efectividad de } \\
\text { los derechos reconocidos por la ley } \\
\text { sustancial, puesto que se conjugan } \\
\text { diversos aspectos de relevancia } \\
\text { constitucional que deben tenerse en } \\
\text { cuenta al momento de construir un } \\
\text { criterio hermenéutico. }\end{array}$ \\
\hline 83305 & STL 3703- 2019 & $\begin{array}{l}\text { Corte Suprema } \\
\text { De Justicia, Sala } \\
\text { Laboral. }\end{array}$ & $\begin{array}{l}\text { Se toma en cuenta la tesis de la } \\
\text { Corte Constitucional (Sentencia } \\
\text { T-341 de 2018), precisando que se } \\
\text { debe flexibilizar la nulidad de pleno } \\
\text { derecho contenida en la norma, } \\
\text { siempre y cuando se respete la } \\
\text { garantía del plazo razonable; pues lo } \\
\text { efectos que aquella genera implica } \\
\text { una mayor demora del proceso. }\end{array}$ \\
\hline
\end{tabular}




\begin{tabular}{|c|c|c|c|}
\hline $\begin{array}{c}11001-02-03- \\
000-2019-01830\end{array}$ & STC 12660-2019 & $\begin{array}{c}\text { Corte Suprema De } \\
\text { Justicia, Sala De } \\
\text { Casación Civil. }\end{array}$ & $\begin{array}{l}\text { Se expone una nueva consideración } \\
\text { respecto del término para dictar } \\
\text { sentencia, manifestando que este } \\
\text { no corre de forma objetiva, sino } \\
\text { que por su naturaleza subjetiva } \\
\text { ha de consultar realidades de } \\
\text { cada proceso; como el cambio de } \\
\text { titularidad de un despacho vacante. }\end{array}$ \\
\hline D-12981 & T-44319 & $\begin{array}{c}\text { Sala Plena } \\
\text { de la Corte } \\
\text { Constitucional. }\end{array}$ & $\begin{array}{l}\text { La Corte determina como medida } \\
\text { legislativa incompatible a la } \\
\text { Constitución Política la nulidad } \\
\text { contemplada en la norma, pues } \\
\text { además de no contribuir a la } \\
\text { materialización de una justicia } \\
\text { oportuna, resulta ser un obstáculo } \\
\text { para lograr ese objetivo porque } \\
\text { entorpece el desarrollo tanto de } \\
\text { los trámites que se surten en la } \\
\text { administración de justicia como el } \\
\text { funcionamiento del sistema judicial } \\
\text { como tal. }\end{array}$ \\
\hline
\end{tabular}

De las decisiones asumidas en el tema, podemos sostener que los jueces de la CSJ en su sala de Casación Civil, al interpretar el capítulo que les encomendaron de la novela en cadena, no le otorgaron la más conveniente, pues solo tuvieron en cuenta en su enfoque la finalidad que perseguía el legislador, consistente en establecer plazos razonables para dictar sentencia dentro del proceso. Omitieron en la novela que escribían, que dicha norma no aportaba a la consecución de la mejor interpretación posible, sino, la mejor interpretación querida por el legislador. De esa manera, al querer materializar el derecho a un plazo razonable planteando una nulidad con un carácter insaneable, desconocían otras garantías procesales como lo son el acceso efectivo a la administración de justicia, el derecho al debido proceso y el principio de prevalencia del derecho sustancial sobre las formas, cuyo propósito esencial es reconocer que el proceso no es un fin en sí mismo, sino un medio para alcanzar otros fines.

Lo anterior se explica porque al contener la norma una nulidad insaneable y una sanción de perdida de competencia del juez por vencimiento del término para concluir la respectiva instancia, en la práctica esto llevaba a tener que anular la decisión judicial aunque con ella se resolviera conforme al derecho positivo la controversia; lo que a su vez implicaba prolongar más allá de los plazos previstos por la norma la resolución del caso, debido a que el funcionario que perdía competencia debía enviar el proceso al juez que le seguía en turno para llevar a cabo nuevamente todas las actuaciones, inclusive las relativas a la recolección del material probatorio, que ya habían sido adelantadas pero que fueron 
declaradas nulas de pleno. De esta manera no era posible que los sujetos procesales tuvieran una garantía real y efectiva de que la controversia fuera resuelta en un plazo razonable.

A partir de lo expusto es plausible deducir que los novelistas de la cadena no tuvieron en cuenta la dimensión ética de la decisión judicial al momento de interpretar el contenido del artículo 121. El desafuero se veía reflejado en las consecuencias sociales de su interpretación, esto como se dijo, producto de olvidar aplicar la dimensión ética. De esa manera y con el fin de imprimirle celeridad a los procesos a través de una sanción procesal, no se tuvo en cuenta, que ello no solo no contribuía a tal objetivo sino que se convertía en un obstáculo para su consecución impactando de manera en otros principios y derechos fundamentales.

La decisión de exequibilidad emitida por la Corte Constitucional al interpretar el mismo artículo, realiza un análisis que introduce en los argumentos, una realidad social y la posibilidad que exista un abuso del derecho en la interpretación asumida por la Sala de Casación Civil de la CSJ, aplicando con esto el sentido pragmático que debe tener la dimensión ética para reflejar la consecuencia de la justicia. Es cierto que juzgar a partir de consecuencias supone necesariamente aplicar un razonamiento empírico ${ }^{51}$, que se asume a partir de una regla de la experiencia, y que en él inciden las convicciones de quien lo realiza. Tengamos en cuenta, que la metodología dworkiniana del juez Hércules, más allá de ser objetiva, propender por llevar un mensaje que debe alcanzarse en la mayor medida de lo posible.

La inexequibilidad de la disposición por parte de la Corte Constitucional, termina demostrando como la falta de entendimiento de la integridad del derecho y la idea de la novela en cadena, inciden en la creación e interpretación de la ley. Si bien se pone de presente en la discusión un conflicto entre principios que sirven de base a una interpretación; la falta de aplicación de lo que debe entenderse como la mejor interpretación posible, de cara a la noción de justicia, incide de manera significativa en las decisiones asumidas. Así, las 2 primeras decisiones de la CSJ, fueron limitadas dentro de su visión de integridad, tomaron en cuenta únicamente la visión del legislador. Este tipo de visiones termina desconociendo la complejidad de la decisión judicial ${ }^{52}$, y redunda gravemente en la concreción del valor de la justicia.

\footnotetext{
51 Este tipo de razonamiento toma en consideración las reglas de la experiencia del juez. Somos de la tesis que la experiencia es una fuente con la que cuenta el juez al momento de decidir, y ella no se limita únicamente al razonamiento probatorio; esta se caracteriza por constituirse en enunciados universales dentro de un razonamiento, y se componen por percepciones sensoriales construidos a partir de la experiencia perceptiva. Para ABEL LLUCH (2015) p. 46; se trata de reglas no jurídicas, de carácter valorativo derivadas de la lógica, la experiencia y la ciencia que sirven para fundar una valoración razonada de la prueba y permiten su control posterior por otro órgano superior. Puede criticarse la idea que la experiencia constituye una fuente de derecho, sin embargo consideramos que es desconocer totalmente la sinergia del juicio de proporcionalidad que toma como base la Corte Constitucional, especialmente cuando aplica el principio de proporcionalidad en sentido estricto, el cual sosteniéndose en ALEXY; requiere necesariamente determinar la seguridad de las apreciaciones empíricas al momento de asignar los pesos imaginarios a los derechos fundamentales en conflicto, juicio este que necesariamente incorpora la experiencia de quien lo lleva a cabo.

52 Sobre la complejidad de la decisión judicial encontramos a GUETTE (2019) pp. 259-279; quien expresa que no puede entenderse el proceso como un mero juicio silogístico, y más allá existen en algunos eventos circunstancias que exceden la previsión del juez al momento de llevar a cabo un control previo del proceso.
} 
Empero, la sala de Casación civil de la CSJ, no solo obvió aplicar una dimensión ética de la decisión; aplicó en indebida forma la dimensión metodológica. Esto en la medida que solo utilizó criterios de coherencia local, sin analizar dentro del sistema en total, si podía encontrar otro tipo de conexiones lógicas que pudieran otorgar diversas respuestas para elegir entre ellas.

Como lo señala Dworkin, cada juez debe verse a sí mismo al sentenciar un nuevo caso, como un eslabón en la compleja cadena de una empresa en la que todas aquellas innumerables sentencias, decisiones, estructuras, convenciones y prácticas, son la historia, siendo su responsabilidad la de continuar esa historia hacia el futuro. Debe pensar que debe interpretar lo que ha venido ocurriendo porque tiene la responsabilidad de hacer progresar esa empresa que tiene entre manos. Reiteramos, esa empresa debe verse en un conjunto, con todas sus divisiones. En este caso no fue así, insistimos, pues solo con revisar decisiones previas de la Corte Constitucional, era posible preservar la cadena y garantizar la coherencia necesaria para escribir la novela, ipero no!, se olvidó la Sala de Casación Civil de la CSJ, que existían una serie de decisiones sobre el principio de prevalencia del derecho sustancial sobre las formas y que ellas ejercían un efecto al interior del sistema.

En efecto, la Corte Constitucional desde 1995 con la sentencia C-029 de 1995 había venido sosteniendo que "las formas no deben convertirse en un obstáculo para la efectividad del derecho sustancial, sino que deben propender por su realización. Es decir, que las normas procesales son un medio para lograr la efectividad de los derechos subjetivos y no fines en sí mismas"53. Si al menos se hubieran tomado en consideración las sentencias que sobre el tema se habían emitido, las posibilidades decisorias hubieran sido distintas.

53 Encontramos además la sentencia C-596 de 2000, y C- 131 de 2002 donde se lleva a cabo un recorrido importante para sostener que el derecho procesal se encuentra impregnado por el derecho constitucional, dejando de lado el positivismo riguroso que de otrora guiaba la visión interpretativa de los jueces. Sostuvo la Corte Constitucional: "Uno de los espacios en los que mayor incidencia ha tenido el constitucionalismo es el derecho procesal. En la tradición del positivismo formalista el derecho procesal estaba desprovisto de una vinculación sustancial con lo que era materia de litigio; se agotaba en una ritualidad cuya configuración se realizaba fundamentalmente en la instancia legislativa; era ajeno a propósitos que lo conectaran con los fines estatales y la protección de las garantías que lo integraban solo se brindaba en esas actuaciones y bajo los estrechos parámetros de protección establecidos por el legislador. Así, no llamaba a interés el hecho de que, en materia de derechos, la sustancia que se tenía entre manos se desvaneciera ante las ritualidades y formalidades de unos procedimientos que las más de las veces se explicaban por sí mismos y que perdían puntos de contacto con lo que era objeto de controversia.

Pero esa dimensión del derecho procesal ha sido superada pues el constitucionalismo ha rescatado las garantías centenariamente elaboradas como contenidos del derecho procesal para vincularlas inescindiblemente a la realización de las normas sustanciales. Las ha dotado de una teleología que no se explica a partir del solo rito o procedimiento sino en relación directa con las normas jurídicas que consagran los efectos jurídicos que las partes pretenden. Las ha redimensionado para darles ahora el carácter de facultades irrenunciables, históricamente consolidadas y positivizadas; esto es, para advertir en ellas derechos fundamentales.

Con ello, ha dotado al proceso de una nueva racionalidad pues ya no se trata de agotar ritualismos vacíos de contenido o de realizar las normas de derecho sustancial de cualquier manera sino de realizarlas reconociendo esas garantías irrenunciables pues su respeto ineludible también constituye una finalidad del proceso (...)”.

También se encuentran dentro de todo el desarrollo de la línea existente sobre el exceso de ritual manifiesto. Sin ser exhaustivos podemos citar las siguientes decisiones: T-1306 de 2001, T-1123 de 2002, T-950 de 2003 , T-974 de 2003, T-289 de 2005, T-1091 de 2008, T-052 de 2009, T- 264 de 2009, T-268 de 2010; entre muchas otras. 
Vale decir, y sin la pretensión de tener la última palabra, que de buena fe, tanto la Sala de Casación Civil de la Corte como la comisión redactora, quisieron garantizar decisiones basadas en un criterio de coherencia e integridad, ello al imbuir al proceso una visión de celeridad y eficiencia en el desarrollo de la figura del plazo razonable, fijando para ello términos objetivos de 1 año para la primera instancia y 6 meses para la segunda, cuyo propósito era "condicionar a la justicia a que exprese el fallo en un plazo considerable y razonable" 54 .

La sala de Casación Civil de la CSJ al reafirmar un precedente sobre la mora judicial $^{55}$, quiso siempre desarrollar una tesis que tuviera como finalidad conminar a los operadores judiciales a actuar de manera diligente reflejado en una pronta solución de los procesos que los funcionarios judiciales tienen a su cargo. A esta siempre le preocupó el tiempo requerido para tramitar los juicios, predicando entonces que ellos no se deben someter a plazos interminables, de nunca acabar, y aduciendo que solo habría justicia si las controversias se resuelven rápida y cumplidamente, para que de esta manera la ciudadanía, crea en sus jueces y en el Estado, porque sus litigios se decidirán prontamente y sin dilaciones. Sin embargo, bien anotaba Rueda Fonseca ${ }^{56}$ para el 2014, que la fijación de un plazo razonable si bien constituye un logro normativo, el mismo supone al tiempo una talanquera, en tanto se lleva a cabo un presión por vía normativa sobre los jueces, pensando en rebajar tiempos, pero sin hacer una reingeniería del enfoque oral en la administración y gestión del proceso que continúa como modelo que hizo crisis en el $\mathrm{CPC}^{57}$; anunciando en ese momento que esa figura "no promete nada" y que a la postre suponía un resquebrajamiento de la justicia al poner un término de caducidad para el ejercicio de la expresión de la soberanía del aparato judicial.

Consideramos que el gran error radicó en este aspecto, al querer sostener la garantía de plazo razonable de manera objetiva, omnímoda, o prima facie, sobre toda la estructura principalista del código, la constitucional, e inclusive, sobre la realidad social; al punto de sostener de manera tozuda, que se trataba de un plazo objetivo, que no podía sanearse de ninguna manera, lo que aunado al paradigma hermenéutico que se quiso sostener rompió la cadena que debía seguir la novela, desembocando en la expulsión del sistema de la disposición mediante una sentencia de exequibilidad.

Así las cosas, esta declaratoria de inconstitucionalidad de la expresión "de pleno derecho", era una crónica de una muerte anunciada, por su falta de integridad. La sentencia T -341 del 2018 fue el primer anuncio que desembocó con su inconstitucionalidad mediante sentencia C-443 de 2019.

\section{BIBLIOGRAFÍA CITADA}

Abel LluCh, Xavier (2015): Las reglas de la sana crítica (Madrid, La ley). Alchourrón, Carlos y bulygin, Eugenio (2013): Sistemas normativos (Bogotá, Astrea).

\footnotetext{
54 Rueda (2017) pp. 33-78.

55 Corte Suprema de justicia Sala de Casación Civil, STC9996, 2019.

56 Rueda (2017) pp. 33-78.

57 Término utilizado para referirse al anterior código procesal civil.
} 
Alexy, Robert (2007): Teoría de la argumentación jurídica (Madrid, Centro de estudios políticos y constitucionales).

Alexy, Robert (2012): Teoría de los derechos fundamentales (Madrid, Centro de estudios políticos y constitucionales).

Atienza, Manuel (2005): Las razones del derecho (México, Universidad Nacional de México). Berajano, Ramiro (2019): “Corte Constitucional vs. Código General del Proceso”. Disponible en: https://www.ambitojuridico.com/noticias/columnista-impreso/procesal-ydisciplinario/corte-constitucional-vs-codigo-general-del. Fecha de consulta: 13 de enero de 2020.

Bernal, Carlos (2008): El Neoconstitucionalismo a debate (Bogotá, Universidad Externado).

Bobвio, Norbeto (1992): Teoria General Del Derecho (Bogotá, Temis).

Calvo, Manuel (1994): Los fundamentos del método jurídico: Una revisión critica (Madrid, Tecnos).

Chamorro, Francisco (1994): La Tutela Judicial Efectiva Derechos y garantías procesales derivados del artículo 24.1 de la Constitución (Barcelona, Bosch).

Dworkin, Ronald (1988): El imperio de la justicia (Barcelona, Gedisa).

Dworkin, Ronald (1989): Los derechos en serio (Barcelona, Ariel).

Dworkin, Ronald (2007): La justicia con toga (Madrid, Marcial Pons).

Dworkin, Ronald (2008): La democracia posible (Barcelona, Paidos).

Dworkin, Ronald (2014): Justicia para erizos (México, Fondo de Cultura Económica).

Ferrajoli, Luis (2006): Garantismo (Madrid, Trotta).

FINNIS, John (2011): Natural law and natural rights (Gread Bretain, Oxford University Press).

García, Juan (2015): "Pidiendo el principio, Dworkin y la teoría del Derecho en serio", en. Sauca, Jose (dir.), El legado de Dworkin a la filosofía del derecho. Tomando en serio el imperio del erizo (Madrid, Centro de estudios constitucionales) pp. 127-157.

García, Juan (2003): Ensayos de filosofía jurídica (Bogotá, Temis).

GarCía, Gabriel (1981): Crónica de una muerte anunciada (Bogotá, La oveja negra, primera edición).

Guette, David (2019): "El sentido del fallo contemplado en el artículo 373.5 del Código general del Proceso: lo inane de la figura”, Revista de derecho privado, Universidad Externado de Colombia, No 36: pp. 259-279.

Guette, David (2019): “Si P entonces Q. Lógica, instanciación y norma: la importancia de la lógica en el razonamiento legal y la práctica judicial”, Revista Filosofía UIS, Vol. 18, No 2: pp. 208-233.

IsAZA, Juan (2020): Interpretación legal y jurisprudencial (Barranquilla, Universidad del Norte).

Kelsen, Hans (2013): Teoría pura del derecho (Bogotá, Geminis).

Lopez, Diego (2006): Interpretación Constitucional (Bogotá, Unibiblos).

MANRIQUe, Edgar (2014): El libro negro de la interpretación jurídica (Bogotá, Abadía Jurídica Limitada).

MACCORMICK, Neil (1978): Legal reasoning and legal theory (Gread Bretain, Oxford University Press).

MendocA, Daniel (2008): Las claves del derecho (Barcelona, Gedisa). 
Moreso, Jose y vilajosana, Josep (2004): Introducción a la teoría del derecho (Barcelona, Marcial pons).

Ost, François y VAn De KerChove, Michael (2018): ¿De la piramide a la red? Por una teoría dialectica del derecho (México, Libitum).

Pérez Bermejo, Juan (2015): El concepto de integridad en la teoría del derecho como integridad (Madrid, Centro de estudios politicos y constitucionales).

Portocarrero, Jorge (2016): La ponderación y la autoridad del derecho (Madrid, Marcial Pons).

Prieto, Luis (2011): Apuntes de teoría del derecho (Madrid, Trotta).

Rojas, Miguel (2016): Salto al Código General del Proceso (Bogotá, Esaju).

RuedA, Maria (2017): "El proceso civil a partir del código general del proceso”, en Cruz, Horacio (coord.), La raíz del código general del proceso: una mirada concéntrica (Bogotá, Uniandes) pp. 33-78.

RuIz, Mario (2006): “Coherencia lógica y sistema jurídico”, en GARCíA, Alonso (coord.), Racionalidad y derecho (Madrid, Centro de estudios políticos y constitucionales) pp. 23-44.

Solano, Henry (2016): Introducción al estudio del derecho (Medellín, Universidad pontificia bolivariana).

Tejeiro, Octavio (2017): "El proceso civil a partir del código general del proceso", en Cruz, Horacio (coord.), Principios generales del nuevo código general del proceso (Bogotá, Uniandes) pp. 1-32.

Valencia, Arturo (1987): Derecho civil, parte general y personas. Tomo I (Bogotá, Temis).

VIEHWEG, Theodor (2007): Tópica y jurisprudencia. (Pamplona, Arazandi).

Zagrebelsky, Gustavo (2008): "La constitución y sus normas", en Carbonell, Miguel (Comp.), Teoría de la constitución. Ensayos escogidos (México, Porrua) pp. 67-92.

\section{NORMAS CITADAS}

Ley No 1564 (12/7/2012), Código General del Proceso.

Constitucional Política de Colombia (4/7/1991).

Decreto 1400 de 1970 (6/8/1970), Código de Procedimiento Civil.

\section{JURISPRUDENCIA CITADA}

Corte Constitucional. Sentencia del 31 de enero de 2001. Magistrado Ponente: José Hernández Galindo. Sentencia C-095.

Corte Constitucional. Sentencia del 30 de abril de 2002. Magistrado Ponente: Marco Gerardo Monroy Cabra. Sentencia C-316.

Corte Constitucional. Sentencia del 29 de junio de 2004. Magistrado Ponente: Marco Gerardo Monroy Cabra. Sentencia C-622.

Corte Constitucional. Sentencia del 24 de febrero de 2016. Magistrado Ponente: Jorge Iván Palacio Palacio. Sentencia C-086.

Corte Constitucional. Sentencia del 24 de agosto de 2018. Magistrado ponente: Carlos Bernal Pulido. Sentencia T-341. 
Corte Constitucional. Sentencia del 21 de octubre de 2019. Magistrado Ponente: Luis Guillermo Guerrero Pérez. Sentencia C-433.

Corte Constitucional. Sentencia del 06 de diciembre de 2001. Magistrado Ponente: Marco Gerardo Monroy Cabra. Sentencia T-1306.

Corte Constitucional. Sentencia del 12 de diciembre de 2002. Magistrado Ponente: Álvaro Tafur Galvis. Sentencia T -1123.

Corte Constitucional. Sentencia del 16 de diciembre de 2003. Magistrado Ponente: Eduardo Montealegre Lynett. Sentencia T-950.

Corte Constitucional. Sentencia del 22 de octubre de 2003. Magistrado Ponente: Rodrigo Escobar Gil. Sentencia T-974.

Corte Constitucional. Sentencia del 31 de marzo de 2005. Magistrado Ponente: Marco Gerardo Monroy Cabra. Sentencia T-289.

Corte Constitucional. Sentencia del 6 de noviembre de 2008. Magistrado Ponente: Manuel José Cepeda Espinosa. Sentencia T-1091.

Corte Constitucional. Sentencia del 30 de enero de 2009. Magistrado Ponente: Manuel Cepeda Espinosa. Sentencia T-052.

Corte Constitucional. Sentencia del 3 de abril de 2009. Magistrado Ponente: Luis Ernesto Vargas Silva. Sentencia T-264.

Corte Constitucional. Sentencia del 19 de abril de 2010. Magistrado Ponente: Jorge Iván Palacio Palacio. Sentencia T-268.

Corte Constitucional. Sentencia del 24 de mayo de 2000. Magistrado Ponente: Antonio Barrera Carbonell. Sentencia C-596.

Corte Constitucional. Sentencia del 26 de febrero de 2002. Magistrado Ponente: Jaime Córdoba Triviño. Sentencia C-131.

Corte Suprema De Justicia, Sala De Casación Civil. Sentencia del 11 de julio de 2018. Magistrado ponente: Aroldo Wilson Quiroz Monsalvo. Sentencia 8849-2018.

Corte Suprema De Justicia, Sala De Casación Civil. Sentencia del 14 de noviembre de 2018. Magistrado Ponente: Aroldo Wilson Quiroz Monsalvo. Sentencia 148222018/2018-02896.

Corte Suprema de Justicia, Sala de Casación Civil. Sentencia del 7 de noviembre de 2018. Magistrado Ponente: Álvaro Fernando García Restrepo. Sentencia 14507-2018.

Corte Suprema De Justicia, Sala De Casación Civil. Sentencia del 18 de septiembre de 2019. Magistrado Ponente: Luis Alonso Rico Puerta. Sentencia 12660-2019.

Corte Suprema De Justicia, Sala Laboral. Sentencia del 13 de marzo de 2019. Magistrado Ponente: Fernando Castillo Cadena. Sentencia 3703-2019/83305. 
